\title{
Students research the library \\ Using student-led ethnographic research to examine the changing role of campus libraries
}

$\mathbf{W}$ hat do we know about student experiences of the library and their changing needs? Is it possible to capture that kind of information as it emerges in our libraries and use it to modify our services and activities? We contend that not only is it possible, but it is necessary that libraries develop enhanced capacities to sense the changing information landscape and possess the capacity to change with it. The future of academic libraries may depend on it.

New information technologies have changed undergraduate students' college experience, including their research and information needs and practices. ${ }^{1}$ Facing the decentralization of information and resources, academic libraries are attempting to reconfigure their role on campus, modify their collections and physical spaces, and enhance the technological skills of staff in order to meet new needs of students. ${ }^{2}$

As librarians and scholars attempt to document and understand these changes, ethnographic methods have proven insightful for gaining an in-depth look at students' study habits, modes of research, and use of library facilities. In a number of studies, student research participants have shared their daily routines, research strategies, and perspectives on what their libraries do well or could do better. ${ }^{3}$ In most cases, however, students have been the research subjects, not researchers themselves.

In this article we discuss the benefits of student-led ethnographic research on the campus library. Although students may not be able to conduct full-blown research projects (without significant faculty/staff guidance), we suggest that even small-scale projects can provide libraries with valuable insights on student life and perspectives. Such projects provide an opportunity for collaboration between librarians, faculty, and students while providing students with hands-on, mentored research experience. We use our own experience at Illinois State University's (ISU) Milner Library to illustrate the benefits and challenges of student-led research.

\section{Course-based student research on the library}

Built in 1976, Milner Library was designed to maximize the opportunity for quiet study and ready access to research in the book stacks. Over time, the library evolved-instructional labs were added; reference desks, eliminated; new technologies, implemented. In recent years, the library has attempted to be more intentional. The issue for us, as for all libraries, is recognizing the nature and magnitude of changing user behaviors and needs. Statistics and raw numbers identify general trends, but fail to provide more nuanced understandings of underlying causes or processes. As an alternative, ethnographic research-characterized by close observations, interviews, and interactions-allows us to view the library from the perspectives of our students and faculty. And when students

Gina Hunter is associate professor of Anthropology, e-mail: glhunt2@IllinoisState.edu, and Dane Ward is associate dean of Milner Library at Illinois State University, e-mail: dmward@ilstu.edu

(c) 2011 Gina Hunter and Dane Ward 
conduct ethnographic research of their peers, we create opportunities for students to reflect on their own behaviors.

Student research at ISU began in 2008 as a collaboration between associate professor of anthropology, Gina Hunter, and associate dean of the university's Milner Library, Dane Ward. Having a background in anthropology, Ward was interested in using ethnographic methods to understand students' library use and needs to help guide upcoming library renovations. Hunter's interest in having her ethnography students investigate the library stemmed from her work with the Ethnography of the University Initiative (EUI). ${ }^{4}$ In spring 2008, Ward secured funding for two anthropology students to study the library under Hunter's supervision. During the fall semester 2009, a group of students enrolled in Hunter's ethnographic methods course continued the research for their semester project. ${ }^{5}$

Much of what libraries want to know about how students study or conduct research is not amenable to survey research. Students, for example, may be unaware of their own research strategies (which may emerge in-task) or may not share the same vocabulary for their information needs as librarians. Ethnographic methods are useful for capturing the largely unconscious cultural beliefs and practices. Ethnographic research is a family of methods that "involves the ethnographer participating...in peoples' daily lives for an extended period of time, watching what happens, listening to what is said, asking questions-in fact, collecting whatever data are available to throw light on the issues that are the focus of the research. ${ }^{6}$ Although ethnography generally "focuses on the meaning of individuals' actions and explanation, rather than quantification,"7 we allowed students' questions to guide data collection and helped students conduct brief surveys as their inquiries warranted.

It makes sense for students to conduct ethnographic research particularly where students are the research subjects. Students possess a great deal of "native expertise" about their campuses, including other students' academic and social practices, lay vocabulary, and the particularities of the local campus. Students, as researchers, also have relatively easier access to other students than administrators or faculty and, as interviewers, may be able to establish easy rapport with research participants. Therefore, even research projects undertaken by experienced investigators can benefit from incorporating undergraduate students into the research process. Although the final report does not describe the research design in detail, "The Library Study at Fresno State" mentions that students enrolled in ethnographic methods courses participated in data collection for the yearlong ethnographic study, which resulted in a substantial research report with a number or recommendations for the library. Such projects might provide a model for other universities.

For universities and colleges unable to undertake a large-scale ethnographic study, the smaller scale approach of course-based student research can provide valuable data. Such a course might be centered around the library as a topic similar to Michelle Twait's course, "Library as Place" in which students' designed their own ideal library after studying the changing history and purpose of libraries and consulting with architects and university planners. ${ }^{9}$ Although the goal of this project was not to collect data on the library, the students' final project undoubtedly holds valuable information about what students on that campus think about the library.

Another example is Margaret Mellinger's course in usability engineering (UE) at Oregon State University (OSU) in which her students conducted usability studies on the library's Web-based and information technology services. ${ }^{10}$ Students developed research questions, employed common UE methods, and presented their findings and proposed solutions to OSU's library staff at the end of the semester. While such course-based projects do not offer neat and comprehensive research reports, neither do they require research grants or large amounts of funding. Furthermore the studies can be repeated and ongoing. 
Such projects also have the potential to build partnerships between the library staff and faculty from across the campus.

\section{Challenges}

Having students conduct such research poses several challenges. If the research is to be shared and disseminated beyond the classroom, IRB protocols must be developed and approved, ideally before the beginning of the semester. In our case, Hunter worked with ISU's IRB staff to develop a protocol for her ethnography course through which the library research was undertaken. ${ }^{11}$ Another limitation is that novice researchers cannot be expected to acquire relevant background literature and formulate appropriate research questions in the course of one semester. Faculty or librarians can identify key readings and can meet with students throughout the semester to help students narrow their inquiry, make sense of data, and draw conclusions. Given these limitations, students' final research reports are only a starting point for insights.

\section{Our findings}

Student research at Milner Library began with meetings between the students and Hunter and Ward. Our initial question was simply, "What are students doing at the library?" particularly after hours. During both semesters students undertook various kinds of observation exercises. Some observed students entering and leaving the library in the lobby area. Others plotted the use of space on floor maps printed from the library Web site. Yet others observed group and individual study sessions. Taken together, these observations yielded a profile of how the library use changes throughout the day-from quiet solitary study and review for tests earlier in the day to group work and longer stays as the day progressed. The ethnographers' noted that students coming to the library for longer stays tend to "set up camp," an expression that suggests that students establish a personalized space where study, eating, drinking (and even sleeping) over a time will occur. These students spread out on large tables and left their materials in place when they got up to visit the restroom (despite numerous signs warning students not to leave their belongings unattended).

From face-to-face interviews, our students gleaned other insights, such as the finding that their peers are overconfident in their library and search engine skills. In one exercise, the student ethnographer shadowed a senior art history major, "Madison," as she conducted research for a term paper. Madison reported that she had attended a library orientation session and thought herself skilled with search engines and the library catalog. However, the observed search turned out to be ineffective. The ethnographer noted that Madison did not spell well, so she went to Google to find correct spellings of her search terms before returning to the catalog. Madison criticized the library for not having sufficiently up-to-date books on her topic, but did not know that she could use the interlibrary loan service for some of the desired materials. ${ }^{12}$ This one exercise brought to light a number of interesting questions for greater exploration: Was Madison's problem that too much time has lapsed since she received library instruction? Was the assignment unclear? Why did she not ask for help? Further exploration is needed before we can know whether more effective library instruction, technological investments, or alternative approaches to librarianship might be effective in helping students like Madison.

A third example of our research comes from surveys that fall 2009 students conducted. Despite observations that students come to the library in groups and study in groups, the most common reasons students gave for coming to the library were to escape from noise and distraction. Of 86 surveys collected (at two different times of day), 43 students came to the library to find "quiet" and 21 for "less distraction." This is striking given that the literature on digital natives refers to their desire for constant connectedness and their ability to multitask. ${ }^{13}$ Our findings suggest that many students use Milner Library as space for focused work away from normal diversions. Ironically, as our campus becomes increas- 
ingly wired and students have the ability to complete homework and use library sources from anywhere, they choose to study in the library because it allows access to all of those services while offering quiet spaces free of distraction.

Although the projects our students conducted were small, cursory investigations, we learned much about the use of library spaces and students' perspectives. The student researchers benefited in many ways from the opportunity to undertake original research, analyze their results, and reach some preliminary conclusions on the basis of their work. In our experience, student investigators themselves learned much about the library and showed great investment in the research because they knew their work had a ready audience (library staff) and a "real-world" purpose beyond the course.

\section{Conclusion}

The environment in which libraries exist increasingly requires them to possess a diverse and robust toolbox of research methods for understanding the rapidly changing needs and behaviors of students and faculty. The future vitality of academic libraries will depend on their ability to capture information about these emerging changes and to quickly adapt their services and activities. Above all else, this dynamic information world points to the importance of diversifying librarian skill sets to include competence with a wide variety of technologies, assessment methodologies, and strategies for collaborating with students and faculty. Active professional and organizational development initiatives focusing on the integration of these skill sets into the library workplace are urgently needed. Engaging students as vested partners in research on the library will help guide us into the future.

\section{Notes}

1. Alison J. Head and Michael B. Eisenberg, "Finding Context: What Today's College Student Say about Conducting Research in the Digital Age" Project Information
Literacy Progress Report, University of Washington's Information School, February 4, 2009; Shannon Smith, Gail Salaway, and Judith Borreson Caruso, with an Introduction by Richard N. Katz. "The ECAR Study of Undergraduate Students and Information Technology," 2009 (Research Study, Vol. 6). Boulder, CO: EDUCAUSE Center for Applied Research, 2009, available from www. educause.edu/ecar.

2. Bart Harloe and Helene Williams, "The College Library in the 21st Century: Reconfigureing Space for Learning and Engagement," College and Research Libraries News 70, no. 9 (October 2009):514-17; Bryan Sinclair, "The Blended Librarian and the Learning Commons: New Skills for the Blended Library." College and Research Libraries News 70, no. 9 (October 2009):504-16.

3. Andrew Asher, Lynda Duke, and David Green, The ERIAL Project: Ethnographic Research in Illinois Academic Libraries, Academic Commons, posted May 17, 2010; Henry D. Delcore, James Mullooley, and Michael Scroggins, "The Library Study at Fresno State" (Fresno, CA: California State University, Fresno Institute of Public Anthropology, 2009), available from www.csufresno.edu/ anthropology/ipa/TheLibraryStudy(Delcore MulloolyScroggins).pdf; Foster, Nancy Fried and Susan Gibbons. Studying Students: The Undergraduate Research Project at the University of Rochester (Chicago: Association of College and Research Libraries, 2007).

4. The Ethnography of the University Initiative (EUI, www.eui.uiuc.edu) is a multicampus, interdisciplanry project that guides faculty in mentoring student research on their own universities. EUI also offers students the opportunity to archive their work in a publicly accessible online database, the Illinois Digital Environment for Access to Learning and Scholarship (IDEALS), so that future students and others will be able to build upon their work. For more on EUI see: Gina Hunter, Nancy Abelmann, Timothy Reese Cain, Tim McDonough and Catherine Prendergast. "Interrogating the University: One (Archival) Entry at a Time," Change: 
The Magazine of Higher Learning 40 (5) (September/October 2009): 40-45.

5. Spring 2009 student researchers were Bryan Alvarez and James Dale Sauls; the fall 2009 research group included Aaron Borkgren, Victoria More, Rachel Ruona, Jim Stomberg, and Colleen Zwanzig.

6. Martyn Hammersley, and Paul Atkinson, Ethnography: Principles in Practice (London: Routledge, 1995): 1.

7. Karen O'Reilly, Ethnographic Methods (New York: Routledge, 2005): 3.

8. Henry D. Delcore, James Mullooley, and Michael Scroggins, "The Library Study at Fresno State," Fresno, CA: California State University, Fresno Institute of Public Anthropology, 2009, available from www. csufresno.edu/anthropology/ipa/TheLibrar yStudy(DelcoreMulloolyScroggins).pdf.

9. Michelle Twait, "If they build it, they will come: A student-designed library," College and Research Libraries News 70, no. 1 (January 2009): 21-24.
10. Margaret Mellinger, "Library as Laboratory: Computer Science Students Practice Usability Engineering in an Academic Library," Issues in Science and Technology Librarianship 51 (Summer 2007).

11. Students' human subjects research related to Milner Library was conducted in compliance with guidelines approved in protocols \#2008-042 (Spring 2009) and \#2009-0296 (Fall 2009) of the Illinois State University Institutional Review Board.

12. Torri Moré, Colleen Zwanzig, Rachel Ruona, Jim Stomberg, and Aaron Borkgren, (2009) "Understanding Students Use of Technology and Space in Milner Library: An Investigation of Study Habits and Library Use" in the EUI Collection in IDEALS available from hdl.handle. net/2142/16416.

13. John Palfrey and Urs Gasser, Born Digital: Understanding the First Generation of Digital Natives (New York: Basic, 2008). $n$

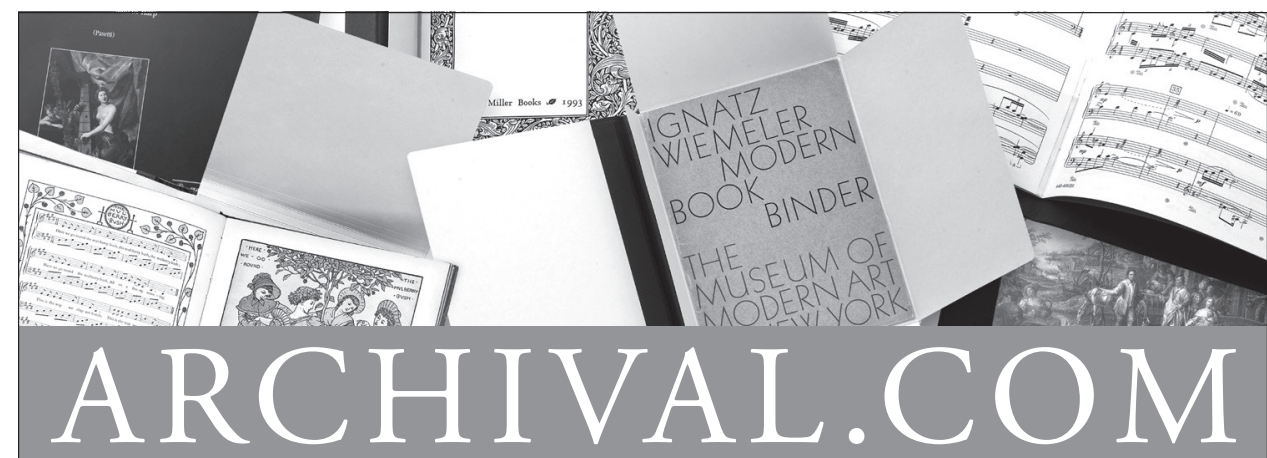

\section{INNOVATIVE SOLUTIONS FOR PRESERVATION}

\section{Call for a complete catalog}

Pamphlet Binders Music Binders Archival Folders Manuscript Folders Hinge Board Covers Academy Folders Newspaper/Map Folders Bound Four Flap Enclosures Archival Binders
Polypropylene Sheet \& Photo Protectors Archival Boards Adhesives

Bookkeeper Century Boxes

Conservation Cloths Non-Glare Polypropylene Book Covers

CoLibri Book Cover System
ARCHIVAL PRODUCTS

P.O. Box 1413

Des Moines, Iowa 50306-1413

Phone: 800.526 .5640

Fax: 888.220.2397

E-mail: custserv@archival.com Web: archival.com 